\title{
Soft-tissue coverage for wound complications following total elbow arthroplasty
}

\author{
Arno A. Macken ${ }^{1}$, Jonathan Lans ${ }^{1}$, Satoshi Miyamura ${ }^{1}$, Kyle R. Eberlin ${ }^{2}$, Neal C. Chen ${ }^{1}$ \\ ${ }^{1}$ Orthopedic Hand and Upper Extremity Service, Massachusetts General Hospital, Harvard Medical School, Boston, MA, USA \\ ${ }^{2}$ Plastic, Reconstructive and Hand Surgery, Massachusetts General Hospital, Harvard Medical School, Boston, MA, USA
}

\begin{abstract}
Background: In patients with total elbow arthroplasty (TEA), the soft-tissue around the elbow can be vulnerable to soft-tissue complications. This study aims to assess the outcomes after soft-tissue reconstruction following TEA.

Methods: We retrospectively included nine adult patients who underwent soft-tissue reconstruction following TEA. Demographic data and disease characteristics were collected through medical chart reviews. Additionally, we contacted all four patients that were alive at the time of the study by phone to assess any current elbow complications. Local tissue rearrangement was used for soft-tissue reconstruction in six patients, and a pedicle flap was used in three patients. The median follow-up period was 1.3 years (range, 6 months-14.7 years).

Results: Seven patients (78\%) underwent reoperation. Four patients (44\%) had a reoperation for soft-tissue complications, including dehiscence or nonhealing of infected wounds. Five patients (56\%) had a reoperation for implant-related complications, including three infections and two peri-prosthetic fractures. At the final follow-ups, six patients (67\%) achieved successful wound healing and two patients had continued wound healing issues, while two patients had an antibiotic spacer in situ and one patient underwent an above-the-elbow amputation. Conclusions: This study reports a complication rate of $78 \%$ for soft-tissue reconstructions after TEA. Successful soft-tissue healing was achieved in $67 \%$ of patients, but at the cost of multiple surgeries. Early definitive soft-tissue reconstruction could prove to be preferable to minor interventions such as irrigation, debridement, and local tissue advancement, or smaller soft-tissue reconstructions using local tissue rearrangement or a pedicled flap at a later stage.
\end{abstract}

Keywords: Arthroplasty; Elbow; Surgical wound dehiscence; Surgical wound infection; Reconstructive surgical procedures

\section{INTRODUCTION}

Total elbow arthroplasty (TEA) is a treatment option in patients with advanced rheumatoid arthritis, osteoarthritis, post-traumatic arthritis affecting the elbow, and complex distal humerus fractures [1]. However, the soft-tissue envelope at the elbow can be of poor quality, particularly after prior surgery, increasing the risk of soft-tissue- and implant-associated complications, especially at the olecranon and in patients with systemic inflammatory disease $[2,3]$. Soft-tissue reconstruction using local tissues, pedicled flaps, or free flaps can be utilized to treat or prevent these complications.

Received: June 30, $2021 \quad$ Revised: August 16, $2021 \quad$ Accepted: August 20, 2021

Correspondence to: Arno A. Macken

Orthopedic Hand and Upper Extremity Service, Massachusetts General Hospital, Harvard Medical School, Suite 2100, 55 Fruit St, Boston, MA 02114, USA

Tel: +1-617-726-4700, Fax: +1-617-724-8532, E-mail: arnomacken@gmail.com, ORCID: https://orcid.org/0000-0002-7513-7437

Financial support: Dr. Lans received personal fees as a consultant for AxoGen. Dr. Chen received personal fees as a consultant for Flexion Medical, Miami Device Solutions, and as a lecturer for DePuy Synthes. Dr. Eberlin received personal fees as a consultant for AxoGen, Integra, and Checkpoint. Conflict of interest: None.

CopyrightC 2021 Korean Shoulder and Elbow Society.

This is an Open Access article distributed under the terms of the Creative Commons Attribution Non-Commercial License (http://creativecommons.org/licenses/by-nc/4.0/) which permits unrestricted non-commercial use, distribution, and reproduction in any medium, provided the original work is properly cited. 
The most common options for soft-tissue reconstruction of the elbow include local tissue rearrangements and pedicled flaps (anconeus, brachioradialis, radial/ulnar forearm, or medial/lateral arm), but free flaps have also been reported (anterolateral thigh, groin, or latissimus dorsi) [3-6]. Infections, wound dehiscence, flap necrosis, seroma formation, and hematomas are potential complications after soft-tissue reconstruction of the elbow, with wound dehiscence being the most common [7,8]. Additionally, wound healing issues may develop due to periprosthetic infections. The implant is generally explanted at the time of soft-tissue reconstruction, but there are many factors involved in such decision making.

Reports on the outcomes of soft-tissue reconstruction in the setting of TEA are limited. Studies with short-term follow-ups have shown the short-term benefits of soft-tissue reconstruction, but longer follow-up complication rates remain high, which is in line with most total elbow arthroplasties [2,3,7,9]. This study aims to assess the soft-tissue related outcomes and the arthroplasty related outcomes after soft-tissue reconstruction following TEA.

\section{METHODS}

We conducted this study in compliance with the principles of the Declaration of Helsinki. The study's protocol was reviewed and approved by the Partners Human Research Committee (study number. 1999P008705). Verbal informed consent was obtained in cases of telephonic follow-ups, while informed consent was waived in cases of retrospectively identified patients that were not successfully contacted for follow-ups.

After Institutional Review Board approval, we identified patients that had an International Classification of Diseases 9th edition procedure code, 10th edition procedure code, or current procedural terminology (CPT) code for soft-tissue reconstruction in combination with a CPT code for TEA (Supplementary Material 1). All patients identified with both sets of codes $(n=30)$ that were treated at a single institutional system including five urban hospitals from the January 1, 2000, to the March 1, 2018, were verified through medical chart reviews. We included all adult patients that underwent soft-tissue reconstructions using local tissue rearrangement or a pedicled flap following TEA. Local tissue rearrangement was defined as adjacent tissue transfers involving rearranging or transferring local areas of the skin along with underlying subcutaneous tissues to cover the defects. Complex wound closure with local tissue advancement was not classified as soft-tissue reconstruction and these patients were not included. Twenty patients were excluded upon manual review be- cause they were miscoded and did not undergo TEA or soft-tissue reconstruction using a flap, while one patient was excluded because a free flap was used for initial soft-tissue coverage, resulting in a final total of nine included patients.

Data regarding patient-, treatment-, and disease characteristics were collected through medical chart reviews. A nonhealing wound was defined as incomplete wound healing per secondary intention requiring additional treatment. Wound dehiscence was defined as the reopening of a previously closed wound requiring additional treatment. A wound infection was defined as an infection of the operated elbow requiring antibiotic treatment and confirmed using microbiological cultures and serologic markers. Serologic markers positive for active infection were defined as a C-reactive protein concentration higher than $13.5 \mathrm{mg} / \mathrm{L}$ or an erythrocyte sedimentation rate higher than $22.5 \mathrm{~mm} / \mathrm{hr}$, with these data being available in seven patients [10-12]. Differentiation between a wound and implant infection was based on the clinical judgement of the treating physician. Reoperation was defined as any unplanned surgery to the ipsilateral elbow, more specifically, reoperations were subdivided into soft-tissue related (revision surgery for soft-tissue complications) or TEA related (replacement or removal of one or more components of the implant) reoperations. Follow-up time was calculated as the time from soft-tissue reconstruction to final clinical or telephone follow-ups.

The patients that were alive at the time of the study $(n=4)$ were contacted by letter or phone to complete questionnaires regarding additional treatment at other institutions and the status of wound healing. We were able to contact all four patients. Long-term outcome data were collected and managed through Research Electronic Data Capture (REDCap, Vanderbilt University, Nashville, TN, USA) tools hosted at our institution. This is a secure web-based application designed for data capture and management of research studies [13].

\section{Study Population}

The nine patients that were included had a median age of 69 years (range, 21-78 years) at the time of soft-tissue reconstruction and the majority of the patients were female $(n=6)$. The median follow-up was 1.3 years (range, 6 months-14.7 years). One patient (case 7) did not undergo reoperations, but also had no records of follow-up and was deceased at the time of the study. In total, five patients were deceased at the time of the study. The median follow-up of the remaining patients was 8.0 years (range, 1.1-14.7 years).

Six patients underwent TEA for rheumatoid arthritis, one patient underwent an osteosarcoma resection followed by TEA, one 
patient underwent a TEA for a distal humerus fracture with underlying rheumatoid arthritis, and one patient exhibited a nonunion of a closed distal humerus fracture. Five patients had bilateral total elbow replacements, but no patients underwent bilateral soft-tissue reconstruction. The elbow of the dominant limb was treated in five patients. Prosthesis designs included Discovery (Zimmer Biomet, Warsaw, IN, USA; $\mathrm{n}=4$ ), Coonrad-Morrey (Zimmer Biomet; $\mathrm{n}=2$ ), and Capitellar Condylar (Stryker, Kalamazoo, MI, USA; $n=1$ ). In two patients, the make of the prosthesis was unknown (Table 1, Figs. 1-3).

After TEA, but prior to soft-tissue reconstruction surgery, all patients had at least one reoperation (range, 1-13), including implant replacement (complete TEA or single component), open reduction and internal fixation, secondary wound closure with local tissue advancement (but no reconstruction requiring soft-tissue rearrangement), triceps repair, radial nerve neurolysis and multiple tendon transfers, elbow scar contracture release, excision of heterotopic ossification, irrigation and debridement (I\&D), and ulnar nerve neurolysis and bursectomy (Table 2). Soft-tissue reconstruction was performed at a median of 9.0 months (range, 1 month-27.6 years) following TEA. Indications for soft-tissue reconstruction included an infected nonhealing wound ( $\mathrm{n}=8$ ) and an ischemic nonhealing wound of the soft-tissue covering the olecranon combined with a seroma $(n=1)$. Six out of eight infections were confirmed with microbiological cultures or serologic markers (Table 3). All infections received antibiotic treatment. The implant was exposed in three patients (cases 1,5 , and 7), but was not exchanged at the initial soft-tissue reconstruction. The olecranon was exposed in three patients (cases 2,4 , and 8). Local tissue rearrangement was used in six patients (cases 1, 2, 4-6, and 9), and a pedicled flap was used in three patients (cases 3, 7, and 8). In two patients, soft-tissue reconstruction was performed in multiple stages (cases 4 and 5) with a flap delay in the first surgery and subsequent inset in a second or third surgery. The defect size at the elbow ranged from 2 to144 $\mathrm{cm}^{2}$ with this information being retrievable from the charts in seven patients (Table 3 ).

\section{RESULTS}

Following soft-tissue reconstruction, seven patients (78\%) underwent reoperation and five patients underwent more than one

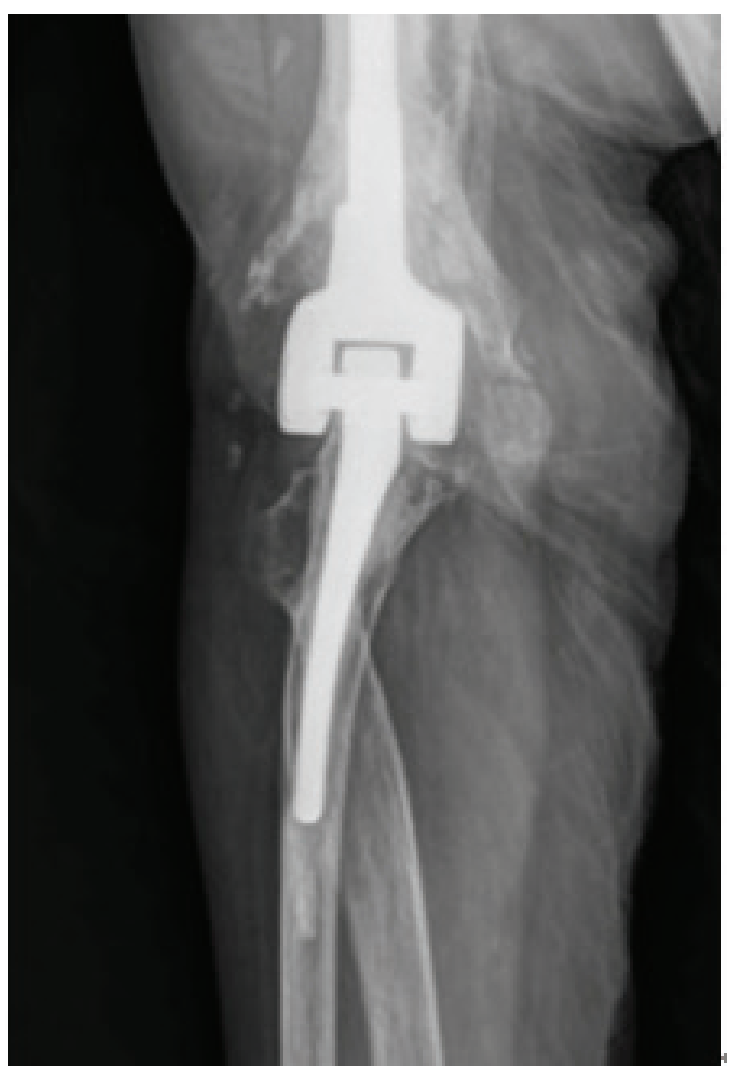

Fig. 1. An anteroposterior radiograph of case 2 showing a total elbow implant in place.

Table 1. Demographics

\begin{tabular}{|c|c|c|c|c|c|c|c|c|}
\hline Case & Sex & Age (yr) & Diagnosis & Implant type & $\begin{array}{c}\text { Surgery on } \\
\text { dominant limb }\end{array}$ & Smoker & Diabetes & $\begin{array}{c}\text { Workers' } \\
\text { compensation }\end{array}$ \\
\hline 1 & Female & 61 & Rheumatoid arthritis & Unknown & No & Yes & No & No \\
\hline 2 & Female & 78 & Rheumatoid arthritis & Biomet discovery & Yes & No & No & No \\
\hline 3 & Female & 74 & Rheumatoid arthritis & Capitellar condylar & Yes & No & No & No \\
\hline 4 & Female & 77 & Rheumatoid arthritis & Biomet discovery & Yes & No & No & No \\
\hline 5 & Male & 74 & Fracture & Coonrad-Morrey & Yes & No & No & No \\
\hline 6 & Female & 69 & Rheumatoid arthritis & Coonrad-Morrey & No & No & No & No \\
\hline 7 & Male & 68 & Rheumatoid arthritis and fracture & Unknown & Yes & Yes & Yes & No \\
\hline 8 & Male & 62 & Rheumatoid arthritis & Biomet discovery & No & Yes & No & No \\
\hline 9 & Female & 21 & Osteosarcoma & Biomet discovery & Unknown & No & No & No \\
\hline
\end{tabular}


reoperation (range, $0-4$ ). The median time to reoperation was 4.6 months (range, 1.4 months-1.9 years). Two patients (22\%) had successful secondary soft-tissue coverage with a single soft-tissue reconstruction and did not require any further operations (cases 7 and 9) (Table 4).

Four patients (44\%) had a reoperation for soft-tissue complications after the primary reconstruction (cases 1-3, and 8), including dehiscence or nonhealing of infected wounds. One patient initially underwent local tissue advancement for wound closure

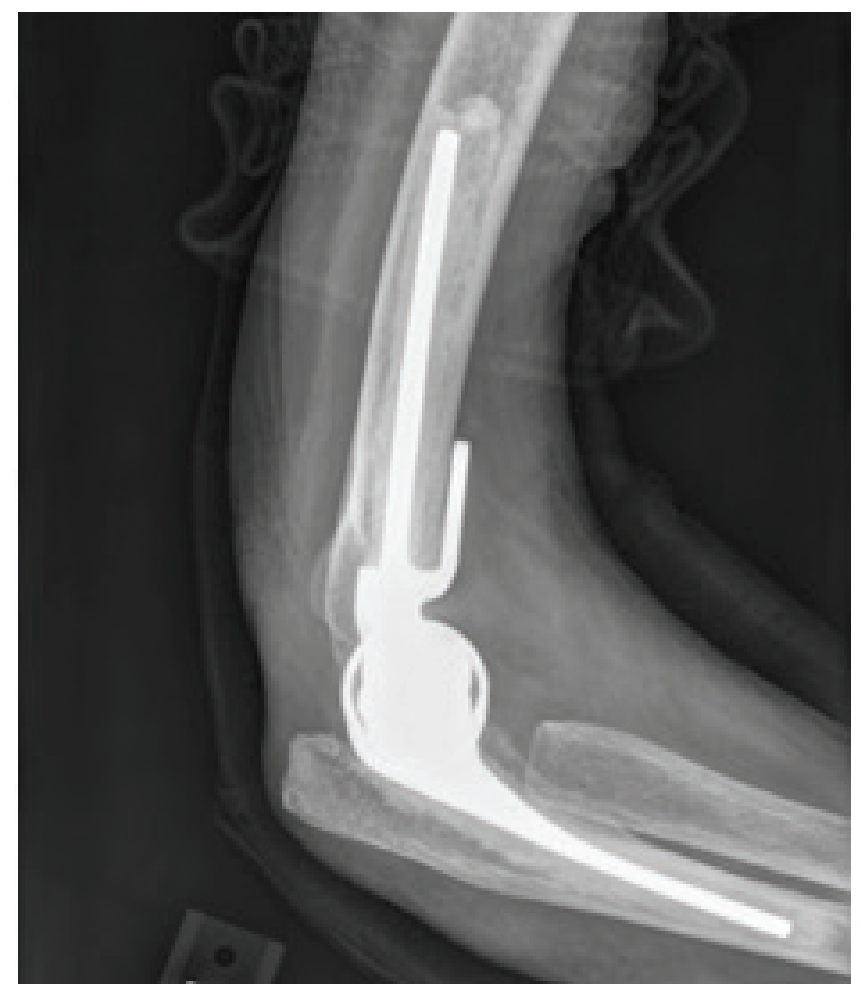

Fig. 2. A lateral radiograph of case 4 showing a total elbow implant in place. (case 8) and four patients eventually underwent additional soft-tissue reconstruction or skin grafts: local tissue rearrangements (cases 2 and 8), a full-thickness skin graft from the medial arm (case 3), and a radial forearm pedicled flap (case 1) were used for secondary soft-tissue reconstructions. Additional local tissue rearrangement (case 8 ) and a pedicled muscle flap, covered by a full-thickness skin graft from the lateral arm (case 3), were used for tertiary soft-tissue reconstruction. One patient (case 3) required a fourth operation for soft-tissue reconstruction for which a split-thickness skin graft from the anterolateral thigh was used. A free flap was not used in any of the patients. At the final follow-up, one patient had an above the elbow amputation (case 2), and two patients had persisting nonhealing wounds (cases 1 and 3).

Median implant survival following soft-tissue reconstruction was three years (range, 2 weeks-14.6 years). There was no patient

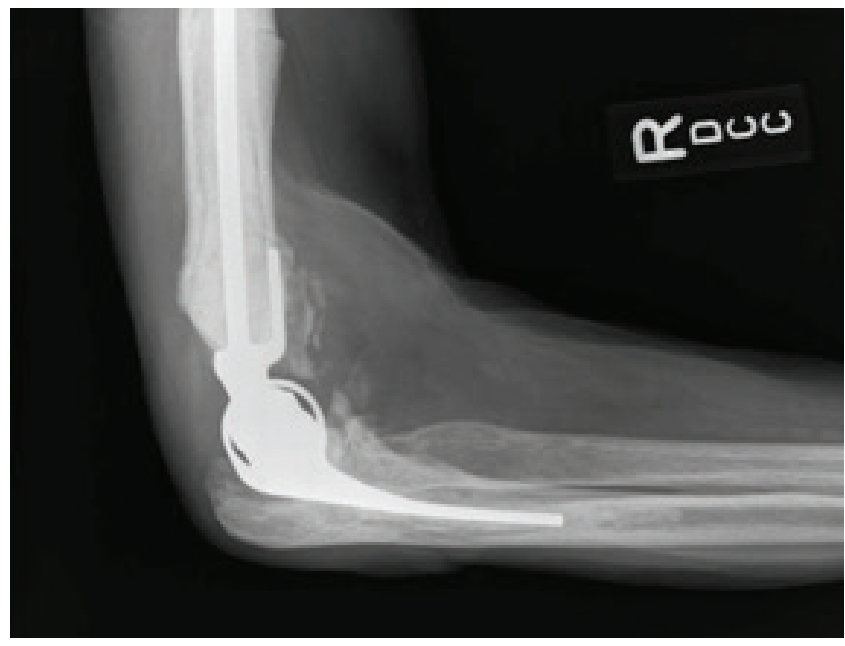

Fig. 3. A lateral radiograph of case 5 showing a total elbow implant in place.

Table 2. Operations before soft-tissue reconstruction

\begin{tabular}{|c|c|c|c|}
\hline Case & $\begin{array}{c}\text { No. of } \\
\text { operations }\end{array}$ & Procedure (n) & $\begin{array}{c}\text { Time to } \\
\text { reconstruction }(\mathrm{yr})\end{array}$ \\
\hline 1 & 13 & $\begin{array}{l}\text { I\&D (5), TEA replacement and triceps repair (2), TEA replacement (2), bushings replacement (1), triceps } \\
\text { repair (1), wound closure with local tissue advancement (1), TEA removal and placement of antibiotic } \\
\text { spacer (1) }\end{array}$ & 27.60 \\
\hline 2 & 2 & $\mathrm{I} \& \mathrm{D}(2)$ & 0.13 \\
\hline 3 & 1 & Elbow scar contracture release (1) & 8.28 \\
\hline 4 & 6 & $\mathrm{I} \& \mathrm{D}(6)$ & 0.05 \\
\hline 5 & 4 & I\&D (3), excision of ossification (1) & 0.80 \\
\hline 6 & 2 & $\mathrm{I} \& \mathrm{D}(2)$ & 11.80 \\
\hline 7 & 5 & Wound closure with local tissue advancement (3), TEA replacement (1), I\&D (1) & 0.71 \\
\hline 8 & 2 & Ulnar nerve neurolysis and excision of bursitis (1), I\&D (1) & 0.32 \\
\hline 9 & 2 & TEA replacement (1), I\&D with placement of antibiotic bead (1) & Unknown \\
\hline
\end{tabular}

I\&D: irrigation and debridement, TEA: total elbow arthroplasty. 
Table 3. Treatment

\begin{tabular}{|c|c|c|c|c|c|c|c|c|}
\hline Case & Indication & $\begin{array}{l}\text { Microbial } \\
\text { culture }\end{array}$ & $\begin{array}{l}\text { Serologic } \\
\text { infection } \\
\text { marker }\end{array}$ & $\begin{array}{l}\text { Antibiotic } \\
\text { treatment }\end{array}$ & $\begin{array}{c}\text { Bone/implant } \\
\text { exposed }\end{array}$ & $\begin{array}{l}\text { Soft-tissue } \\
\text { donor }\end{array}$ & $\begin{array}{l}\text { Reconstruction } \\
\text { technique }\end{array}$ & $\begin{array}{c}\text { Defect size } \\
\left(\mathrm{cm}^{2}\right)\end{array}$ \\
\hline 1 & Nonhealing infected wound & CoNS & Unknown & Yes & Implant & Local & Tissue rearrangement & Unknown \\
\hline 2 & Nonhealing infected wound & CoNS & Positive & Yes & Olecranon & Local & Tissue rearrangement & 2 \\
\hline 3 & Nonhealing infected wound & Nocardia farcinica & Positive & Yes & No & Muscle & Pedicle & 12 \\
\hline 4 & Ischemic nonhealing wound & Unknown & Unknown & No & Olecranon & Local & Tissue rearrangement & 144 \\
\hline 5 & Nonhealing infected wound & Unknown & Negative & Yes & Implant & Local & Tissue rearrangement & $50^{\star}$ \\
\hline 6 & Nonhealing infected wound & MRSA & Positive & Yes & Implant & Local & Tissue rearrangement & $60^{*}$ \\
\hline 7 & Nonhealing infected wound & Unknown & Positive & Yes & Unknown & $\begin{array}{l}\text { Fasciocu- } \\
\text { taneous }\end{array}$ & Pedicle & Unknown \\
\hline 8 & Nonhealing infected wound & Negative & Negative & Yes & Olecranon & $\begin{array}{l}\text { Fasciocu- } \\
\text { taneous }\end{array}$ & Pedicle & $48^{*}$ \\
\hline 9 & Nonhealing infected wound & $\begin{array}{l}\text { Staphylococcus epi- } \\
\text { dermidis }\end{array}$ & Positive & Yes & No & Local & Tissue rearrangement & 32 \\
\hline
\end{tabular}

CoNS: coagulase-negative staphylococci, MRSA: Methicillin-resistant Staphylococcus aureus.

${ }^{\star}$ Covering soft-tissue measured instead of defect.

Table 4. Outcomes

\begin{tabular}{lccccccc}
\hline Case & $\begin{array}{c}\text { No. of } \\
\text { reoperations }\end{array}$ & $\begin{array}{c}\text { Time to } \\
\text { reoperation }(\mathrm{mo})\end{array}$ & $\begin{array}{c}\text { Soft tissue } \\
\text { complication }\end{array}$ & $\begin{array}{c}\text { Implant } \\
\text { revision }\end{array}$ & $\begin{array}{c}\text { Implant } \\
\text { survival (mo) }\end{array}$ & $\begin{array}{c}\text { Deceased } \\
\begin{array}{c}\text { Follow-up } \\
\text { time (yr) }\end{array}\end{array}$ \\
\hline 1 & 3 & 2.84 & Yes & No & 0.51 & Yes & 0.51 \\
2 & 2 & 17.87 & Yes & Yes & 17.39 & Yes & 1.54 \\
3 & 3 & 2.03 & Yes & No & 115.64 & No & 1.10 \\
4 & 1 & 23.51 & No & Yes & 22.88 & No & 10.65 \\
5 & 2 & 4.36 & No & Yes & 4.24 & Yes & 0.52 \\
6 & 1 & 5.64 & No & No & 157.47 & Yes & 0.97 \\
7 & 0 & NA & No & No & Unknown & Yes & $-{ }^{*}$ \\
8 & 4 & 1.35 & Yes & Yes & 54.14 & No & 5.27 \\
9 & 0 & NA & No & No & 175.20 & No & 14.72 \\
\hline
\end{tabular}

NA: not applicable.

${ }^{\star}$ No records of reoperations or follow-up.

where the implant was replaced during soft-tissue reconstruction. There were five patients (56\%) with a reoperation for implant-related complications, including three infections (cases 2, 5, and 6) and two peri-prosthetic fractures (cases 4 and 8). One patient was successfully treated with an I\&D (case 6), while the other four patients required implant revision. Eventually, one patient had the humeral component exchanged (case 4) due to a peri-prosthetic fracture and the entire TEA was removed and replaced with an antibiotic spacer in three patients (cases 2, 5, and 8). At the final follow-ups, six patients still maintained their arthroplasty, of which one was revised after soft-tissue reconstruction (case 4), while two patients had an antibiotic spacer in situ (cases 5 and 8 ) and one patient had an above the elbow amputation (case 2). Other elbow related symptoms at final orthopedic follow-up included pain, weakness, instability, stiffness, and a flail elbow (Fig. 4).

\section{DISCUSSION}

This study aimed to report the outcomes of soft-tissue reconstruction following TEA. All nine patients in this study had multiple surgeries after TEA (range, 1-13) that were eventually complicated by an infection, wound dehiscence or nonhealing wound, and subsequently treated with soft-tissue reconstructions. However, despite these efforts, initial soft-tissue reconstruction was unsuccessful in seven patients. Four patients underwent additional surgery for soft-tissue complications and five patients had implant-related reoperations. At the final follow-ups, soft-tissue healing was achieved in six patients (67\%), while two patients had continued wound healing issues and one patient had an above-the-elbow amputation.

This study was limited by several factors. First, soft-tissue reconstruction is uncommon in patients with TEA. In a large database from five urban hospitals using coding searches followed by 

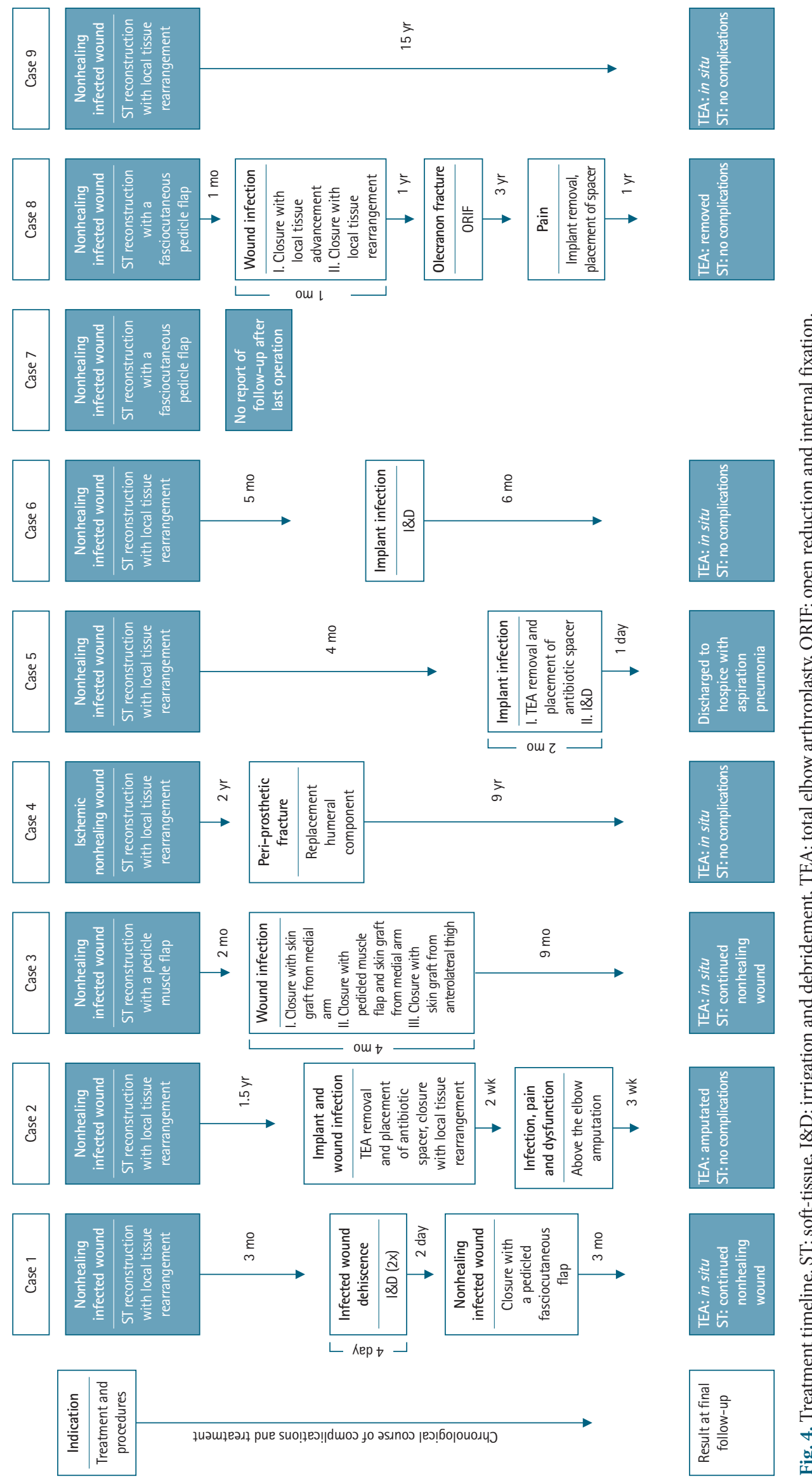
manual reviews, we were able to identify nine patients. It is possible that there were cases in which soft-tissue reconstructions were performed at the time of initial TEA, but this was not coded and would not be identified in our searches. Due to the small cohort, we could not perform a meaningful statistical analysis. Second, only four patients were alive at the time of this study and could be contacted for follow-ups. However, for the remaining patients, follow-up data was obtained retrospectively. Therefore, the results were dependent on coding accuracy and completeness of the medical charts. Furthermore, patients were initially treated with TEA between 1977 and 2009 leading to a variation in treatment, especially considering the evolving surgical and rehabilitation techniques (particularly in microsurgery and soft-tissue reconstruction, as well as implant design). There were also notable differences between the patients in our series in the time from initial surgery to soft-tissue reconstruction, the number of operations before soft-tissue reconstruction, the type of reconstruction used, and treatment by different surgeons. Last, we reported implant and soft-tissue related outcomes separately. However, the two are often related and differentiation was based on clinical judgements.

Our data contrasts two case series that report successful soft-tissue reconstructions using pedicle or rotation flaps after TEA in all patients [3,7]. However, their mean follow-up was 6 months and 26 months, compared to 4.4 years in our study. Our data suggests that long-term complication rates after soft-tissue coverage of TEA are likely higher (78\%). Two studies reported long-term outcomes after soft-tissue reconstruction for TEA related complications [2,9]. Kim et al. [2] reported reoperations in $60 \%$ of the patients $(3 / 5)$ treated with a pedicled radial forearm flap at a mean follow-up of 88 months. One patient received a free flap from the anterolateral thigh and did not have a complication. The mean age was 41 years and none of the patients had rheumatoid arthritis. In contrast, the reoperation rate after soft-tissue reconstruction in our cohort of older patients with rheumatoid arthritis was higher (78\%). Okamoto et al. [9] reported the long-term outcome of one 84-year-old female with rheumatoid arthritis that underwent soft-tissue reconstruction after TEA. At a 3-year follow-up, there were no complications.

The high reoperation rate $(78 \%)$ in our cohort suggests that soft-tissue coverage using delayed attempts at local tissue rearrangement or a pedicled flap may be insufficient in these patients, particularly if there has been prior failure of soft-tissue closure. In total knee arthroplasty, as well as in severe elbow trauma, soft-tissue coverage using a free flap provides positive results, and it is the practice of the senior author to be increasingly ag- gressive about providing durable soft-tissue coverage with a definitive flap early on, prior to the development of soft-tissue complications [5,14-17]. We hypothesize that initial soft-tissue coverage of TEA using a free flap may reduce the reoperation rate. Furthermore, in six patients, an initial attempt was made to treat wound dehiscence surgically (I\&D or local tissue advancement) without definitive soft-tissue reconstruction, but this was unsuccessful in all patients (cases 1, 2, 4, 5, 7, and 8). Eventually, successful soft-tissue coverage was achieved in four out of six of these patients (cases $4,5,7$, and 8 ), but multiple surgeries were needed in all four patients to reach a stable result. In three patients, soft-tissue reconstruction was the primary surgical treatment of wound dehiscence (cases 3,6, and 9). This was successful in two of the three patients, of which one who had to undergo more than one surgery (case 6). This trend suggests that the early recognition of soft-tissue problems, early consultation with a reconstructive surgeon, and initial, aggressive soft-tissue reconstruction instead of minor interventions may reduce the reoperation rate.

Early flap coverage before or during total joint replacement has been suggested in total knee arthroplasties for patients at a higher risk of soft-tissue complications. In total knee arthroplasty, older age and rheumatoid arthritis have been associated with wound healing complications [18]. Andres et al. [19] found that complications were similar between the patients that underwent "prophylactic" coverage and those who underwent a salvage procedure with flap coverage. However, in the salvage group, three patients eventually had an above-the-knee amputation compared to none in the group with "prophylactic" soft-tissue coverage. In general, poor soft-tissue quality and delayed wound healing have been reported in older patients and patients with rheumatoid arthritis [20-22]. Considering the high complication rate in the setting of soft-tissue compromise, early soft-tissue reconstruction at the time of TEA may be preferable in select patients if preservation of the prosthesis is preferred rather than resection arthroplasty.

This study reports high complication rates after soft-tissue coverage for wound complications following TEA, specifically in older patients with rheumatoid arthritis. Successful soft-tissue healing was achieved in $67 \%$ of patients, but at the cost of multiple surgeries. At final follow-up, six out of nine patients had a TEA in place, of which one was revised. Two patients had an antibiotic spacer, and one patient underwent an above-the-elbow amputation. Early soft-tissue reconstruction at the time of TEA may be considered for high-risk patients. When soft-tissue issues occur, early recognition, early consultation with a reconstructive surgeon, and definitive soft-tissue coverage procedures may aid 
in the prevention further sequelae. More research is required to further clarify the decision making in complicated cases.

\section{ACKNOWLEDGMENTS}

The abstract of this work was presented as a poster at the American Association for Hand Surgery Annual Meeting in January 2020.

\section{SUPPLEMENTARY MATERIAL}

Supplementary materials can be found via https://doi.org/10.5397/ cise.2021.00409.

\section{ORCID}

\section{Arno A. Macken \\ Jonathan Lans \\ Satoshi Miyamura \\ Kyle R. Eberlin \\ Neal C. Chen}

https://orcid.org/0000-0002-7513-7437 https://orcid.org/0000-0002-6159-4645 https://orcid.org/0000-0002-2245-5554 https://orcid.org/0000-0003-4427-2588 https://orcid.org/0000-0002-8967-9018

\section{REFERENCES}

1. Lovy AJ, Keswani A, Dowdell J, Koehler S, Kim J, Hausman MR. Outcomes, complications, utilization trends, and risk factors for primary and revision total elbow replacement. J Shoulder Elbow Surg 2016;25:1020-6.

2. Kim HJ, Kim JY, Kee YM, Rhee YG. Total elbow arthroplasty under unfavourable soft tissue conditions. Int Orthop 2018; 42:367-74.

3. Fleager KE, Cheung EV. The "anconeus slide": rotation flap for management of posterior wound complications about the elbow. J Shoulder Elbow Surg 2011;20:1310-6.

4. Hacquebord JH, Hanel DP, Friedrich JB. The pedicled latissimus dorsi flap provides effective coverage for large and complex soft tissue injuries around the elbow. Hand (N Y) 2018;13:58692.

5. Wei FC, Jain V, Celik N, Chen HC, Chuang DC, Lin CH. Have we found an ideal soft-tissue flap? An experience with 672 anterolateral thigh flaps. Plast Reconstr Surg 2002;109:2219-26.

6. Kelley BP, Chung KC. Soft-tissue coverage for elbow trauma. Hand Clin 2015;31:693-703.

7. Stevanovic M, Sharpe F, Thommen VD, Itamura JM, Schnall SB. Latissimus dorsi pedicle flap for coverage of soft tissue defects about the elbow. J Shoulder Elbow Surg 1999;8:634-43.

8. Choudry UH, Moran SL, Li S, Khan S. Soft-tissue coverage of the elbow: an outcome analysis and reconstructive algorithm.
Plast Reconstr Surg 2007;119:1852-7.

9. Okamoto S, Tada K, Ai H, Tsuchiya H. Flexor carpi ulnaris muscle flap for soft tissue reconstruction after total elbow arthroplasty. Case Rep Surg 2014;2014:798506.

10. Greidanus NV, Masri BA, Garbuz DS, et al. Use of erythrocyte sedimentation rate and C-reactive protein level to diagnose infection before revision total knee arthroplasty: a prospective evaluation. J Bone Joint Surg Am 2007;89:1409-16.

11. Rhee YG, Cho NS, Park JG, Song JH. Resection arthroplasty for periprosthetic infection after total elbow arthroplasty. J Shoulder Elbow Surg 2016;25:105-11.

12. Somerson JS, Boylan MR, Hug KT, Naziri Q, Paulino CB, Huang JI. Risk factors associated with periprosthetic joint infection after total elbow arthroplasty. Shoulder Elbow 2019;11:11620.

13. Harris PA, Taylor R, Thielke R, Payne J, Gonzalez N, Conde JG. Research electronic data capture (REDCap): a metadata-driven methodology and workflow process for providing translational research informatics support. J Biomed Inform 2009;42:377-81.

14. Cetrulo CL Jr, Shiba T, Friel MT, et al. Management of exposed total knee prostheses with microvascular tissue transfer. Microsurgery 2008;28:617-22.

15. Markovich GD, Dorr LD, Klein NE, McPherson EJ, Vince KG. Muscle flaps in total knee arthroplasty. Clin Orthop Relat Res 1995;(321):122-30.

16. Koteswara Rao Rayidi V, Prakash P, Srikanth R, Sreenivas J, Swathi K. Anterolateral thigh flap-the optimal flap in coverage of severe elbow injuries. Indian J Plast Surg 2019;52:314-21.

17. Yildirim S, Taylan G, Eker G, Aköz T. Free flap choice for soft tissue reconstruction of the severely damaged upper extremity. J Reconstr Microsurg 2006;22:599-609.

18. Rao AJ, Kempton SJ, Erickson BJ, Levine BR, Rao VK. Soft tissue reconstruction and flap coverage for revision total knee arthroplasty. J Arthroplasty 2016;31:1529-38.

19. Andres LA, Casey WJ, Clarke HD. Techniques in soft tissue coverage around the knee. Tech Knee Surg 2009;8:119-25.

20. Tada M, Inui K, Sugioka Y, et al. Delayed wound healing and postoperative surgical site infections in patients with rheumatoid arthritis treated with or without biological disease-modifying antirheumatic drugs. Clin Rheumatol 2016;35:1475-81.

21. Kadota Y, Nishida K, Hashizume K, et al. Risk factors for surgical site infection and delayed wound healing after orthopedic surgery in rheumatoid arthritis patients. Mod Rheumatol 2016;26:68-74.

22. Bibbo C. Wound healing complications and infection following surgery for rheumatoid arthritis. Foot Ankle Clin 2007;12:50924. 